\title{
Hydrogen Peroxide Gas Generator Cycle with a Reciprocating Pump
}

\author{
J.C. Whitehead
}

This article was submitted to $38^{\text {th }}$ American Institute of Aeronautics and Astronautics/Association for the Study of Medical Education/Automated Software Engineering/American Society for Engineering Education/Joint Propulsion Conference and Exhibit, Indianapolis, IN, July 7 - 10, 2002

U.S. Department of Energy

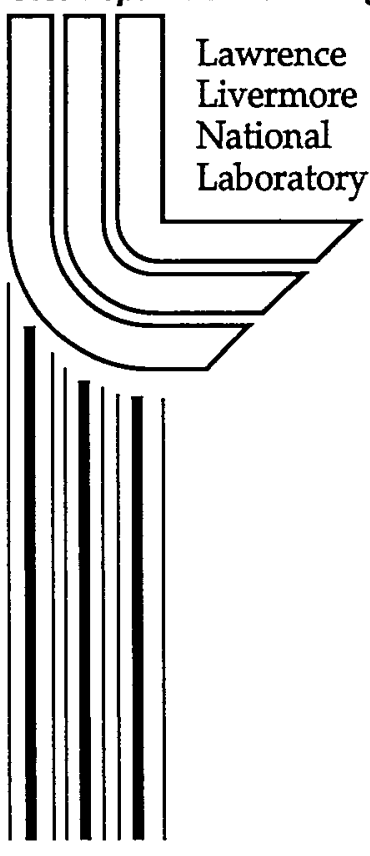

\section{June 11, 2002}




\section{DISCLAIMER}

This document was prepared as an account of work sponsored by an agency of the United States Government. Neither the United States Government nor the University of California nor any of their employees, makes any warranty, express or implied, or assumes any legal liability or responsibility for the accuracy, completeness, or usefulness of any information, apparatus, product, or process disclosed, or represents that its use would not infringe privately owned rights. Reference herein to any specific commercial product, process, or service by trade name, trademark, manufacturer, or otherwise, does not necessarily constitute or imply its endorsement, recommendation, or favoring by the United States Government or the University of California. The views and opinions of authors expressed herein do not necessarily state or reflect those of the United States Government or the University of California, and shall not be used for advertising or product endorsement purposes.

This is a preprint of a paper intended for publication in a journal or proceedings. Since changes may be made before publication, this preprint is made available with the understanding that it will not be cited or reproduced without the permission of the author.

This report has been reproduced directly from the best available copy.

Available electronically at http://www.doc.gov/bridge

Available for a processing fee to U.S. Department of Energy

And its contractors in paper from

U.S. Department of Energy

Office of Scientific and Technical Information

P.O. Box 62

Oak Ridge, TN 37831-0062

Telephone: (865) 576-8401

Facsimile: (865) 576-5728

E-mail: reports@adonis.osti.gov

Available for the sale to the public from

U.S. Department of Commerce

National Technical Information Service

5285 Port Royal Road

Springfield, VA 22161

Telephone: (800) 553-6847

Facsimile: (703) 605-6900

E-mail: orders@ntis.fedworld.gov

Online ordering: http://www.ntis.gov/ordering.htm

OR

Lawrence Livermore National Laboratory

Technical Information Department's Digital Library

http://www.llnl.gov/tid/Library.html 


\title{
HYDROGEN PEROXIDE GAS GENERATOR CYCLE WITH A RECIPROCATING PUMP
}

\author{
John C. Whitehead* \\ Lawrence Livermore National Laboratory \\ Livermore, CA 94551
}

\begin{abstract}
A four-chamber piston pump is powered by decomposed $85 \%$ hydrogen peroxide. The performance envelope of the evolving 400 gram pump has been expanded to $172 \mathrm{cc} / \mathrm{s}$ water flow at discharge pressures near $5 \mathrm{MPa}$. A gas generator cycle system using the pump has been tested under similar conditions of pressure and flow. The powerhead gas is derived from a small fraction of the pumped hydrogen peroxide, and the system starts from tank pressures as low as $0.2 \mathrm{MPa}$. The effects of steam condensation on performance have been evaluated.
\end{abstract}

\section{Introduction}

This paper is an update on progress toward pump-fed rocket propulsion on a small scale, or what amounts to miniaturized launch propulsion technology. Potential applications include small upper stages, maneuvering vehicles, lunar landing and liftoff, and Mars ascent. ${ }^{1}$ As on launch vehicle liquid stages, the underlying principle is the use of low pressure lightweight tanks and compact high pressure thrust chambers to reduce total system hardware mass and improve packaging. Absent, for example, are the gas vessels typical of pressure fed spacecraft systems.

Nearly a decade ago, a miniature pump-fed hydrazine rocket was demonstrated in flight. ${ }^{2}$ Its most significant shortcoming was high warm gas leakage past the powerhead pistons and warm gas valves. One advance in recent years has been the use of conductively cooled soft seals to eliminate this leakage. A recent paper ${ }^{3}$ reviewed these developments and presented initial test results for the latest four-chamber pump by itself at low pressure. More recently, the same hardware has been refined to operate at higher pressures with a smoother output. The latest work, also reported here, has been to run the leaktight pump in a gas generator cycle system.

Another noteworthy difference compared to the prior hydrazine work is that the nontoxic hydrogen peroxide has simplified development testing. The small scale system can be operated on a laboratory bench without thrusters.

*Senior Member, AIAA

Copyright (1) 2002 by the Lawrence Livermore National Laboratory. Pblishedby the American Institute of Aeronatics and Astronatics, hc. with permission. This work was performed under contract W-7405-Eng-48 with the U.S. DoE. $\underline{\text { Reciprocating Pump }}$

Centrifugal pumps powered by turbines are widely used on launch vehicle engines. However, these conventional machines do not readily scale down for thrust levels below about $20 \mathrm{kN}(\sim 5000 \mathrm{lb})$. Tip velocities must remain unchanged for a given pressure, so viscous losses decrease efficiency on a small scale.

An alternative type of pump is conceptually simple. A reciprocating pump for continuous flow consists of at least one pair of chambers which alternately refill at low pressure and expel at high pressure through check valves. Fluid drive is the lightweight choice for rocket applications, and a reciprocating pump lends itself to being powered directly by high pressure gas without rotating machinery.

A reciprocating pump can be thought of as small high pressure tanks which reload from the large low pressure tank. These components together can be lighter than a fully pressurized large tank, since structural mass is proportional to the sum of pressure-volume products. The overall challenge is to package the pump chambers and associated valves into a reliable machine which is sufficiently lightweight and compact for rocket applications. In order to keep fluid velocities low, flow passageways including valves must be sufficiently large.

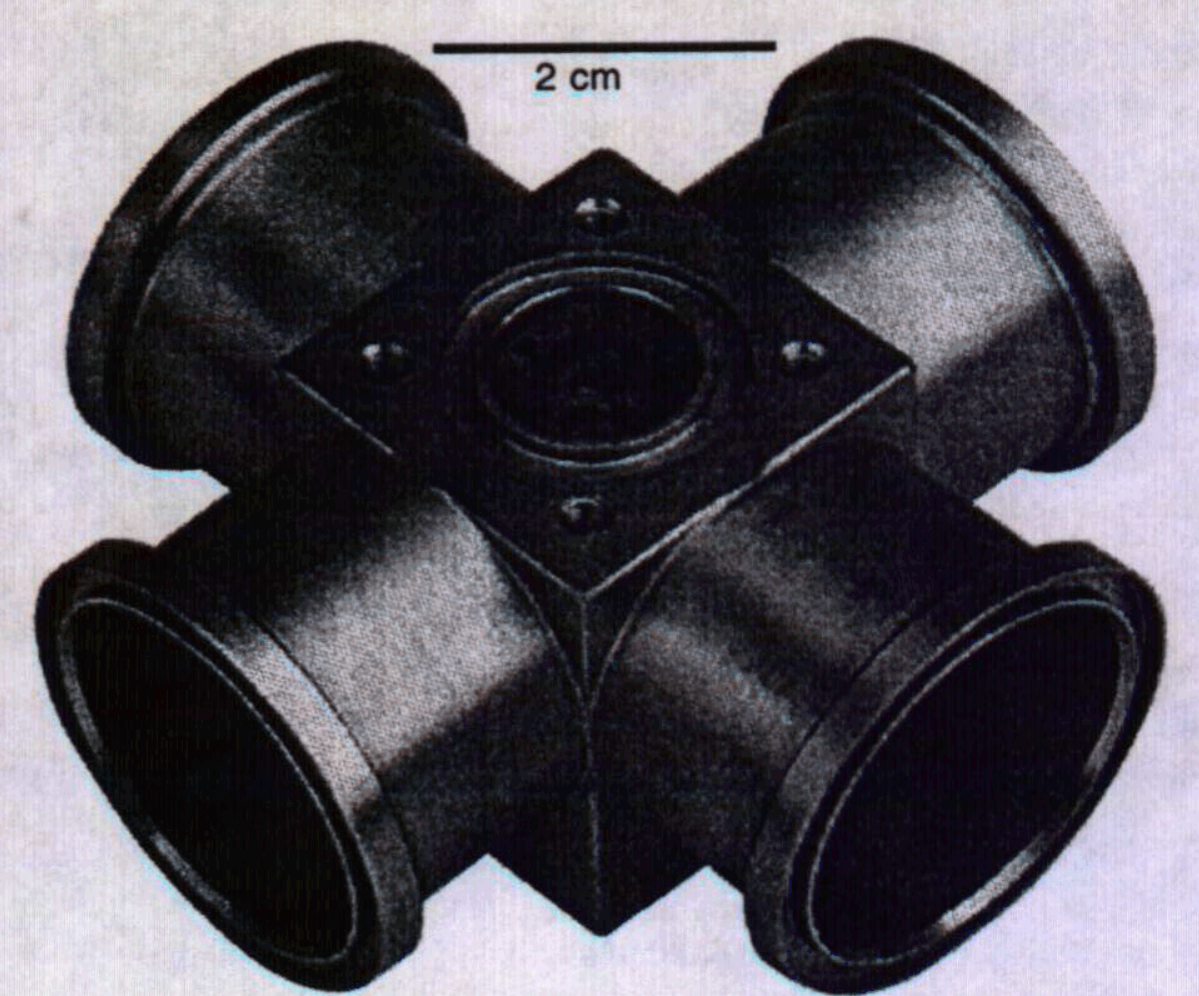

Figure 1. One-piece liquid block and cylinders (62 grams). 
Another issue is separating the pumped liquid from the powerhead gas, which is readily achieved by free pistons. In Figure 1, four cylindrical pump chambers are integral with a central block containing large inlet check valves (for high flow at low pressure), and smaller outlet check valves. The suction port is at the top.

The lower face of the liquid block has four ports for the discharge check valves. Figure 2 shows this side, along with the assembled powerhead parts. The thin tubes control a gas intake and exhaust valve at the end of each cylinder. Pairs of adjacent cylinders operate alternately, so opposite pistons stroke toward each other simultaneously to avoid mass shifts and minimize vibration. At any time, two opposite cylinders are pressurized for propellant delivery, while the others may refill from the tank. Internally, the effective piston area is 1.42 times greater for the gas than for the liquid. This pressure amplification feature permits some of the delivered propellant to flow through a gas generator to power the pump.

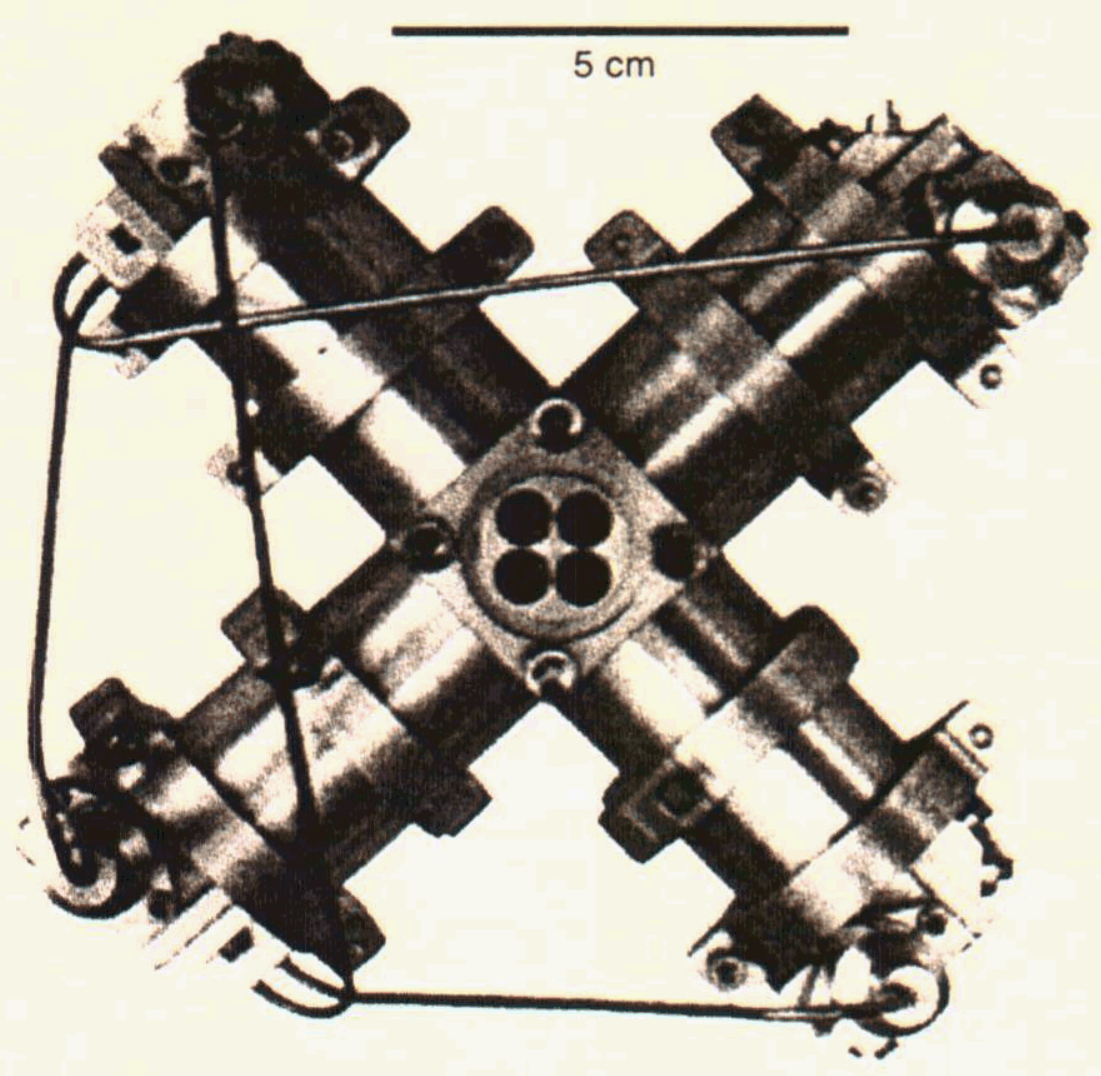

Figure 2. Quad piston pump with leaktight seals (350 g).

The pump mass is $\mathbf{4 0 0}$ grams with the addition of warm gas distribution tubes (not shown). Because the assembly is a modification of an earlier version, it has unnecessary geometrical features that account for 10-20 percent of the mass. Structural optimization would result in further reductions. For example, a cylinder and head was hydrostatically tested to a much higher pressure than necessary (20.7 MPa, $3000 \mathrm{psi})$ without deformation.

A significant improvement over an earlier hydrazine pump is the elimination of warm gas leakage in the powerhead. This has been achieved through the used of soft seals for the power piston and intake-exhaust valves, with gas temperatures approaching $800 \mathrm{~K}(980 \mathrm{~F})$. The pumped fluid serves as a coolant, and the cylinder walls and heads are made of aluminum for high thermal conductivity, low mass, and affordability.

A key design driver for the 1993 pump was a concern of overheating the hydrazine. This led to deliberate thermal isolation of the power cylinder from the pump cylinder. The uncooled powerhead was fitted with solid graphite piston rings, and the resulting leakage meant a continuous heat flux to the pump even when no liquid was flowing. Ironically, this result of the overheating concern in turn justified the concern.

\section{Pump Test Results Update}

During bench testing, a pump is mounted to a water tank held at $0.35 \mathrm{MPa}(50 \mathrm{psi}$ ), and a high pressure gas source is connected. Unlike turbopumps, a reciprocating pump readily maintains full pressure at no flow, with no motion and no expenditure of fluid power. Under this condition, maximum pressure is obtained. Opening a discharge valve starts the flow with essentially no delay. The pump pistons follow the fluid, and the valves cycle at the endpoints of each piston stroke. Cycling frequency depends entirely on flow, which may be throttled continuously from zero to maximum capacity.

Reciprocating pumps necessarily have switching transients when the valves move and each adjacent cylinder starts pumping. The smoothness of the discharge pressure is a key performance parameter, and achieving smooth operation has been a challenge. Continued refinement and testing over the past year has resulted in a significant improvement. This yields a higher average liquid pressure relative to the gas drive pressure, which was also increased.

Measured data consists of pressures, temperatures, discharge volume, time of operation, and the quantity of high-test hydrogen peroxide (HTP) which is decomposed to power the pump. Calculated information includes average flows, average pressures, and effective gas density.

Figure 3 shows pressure traces and other data for one test. The ratio of the mean non-flowing pressures indicated is 1.41 , essentially equal to the piston area ratio. The same ratio at full flow is 1.33 , which is indicative of pressure drops in the gas intake valve and the liquid discharge check valve. In spite of these losses, there is plenty of margin for the pump to be driven by its own discharge fluid in a gas generator cycle (a vast improvement over Reference 3 ). 


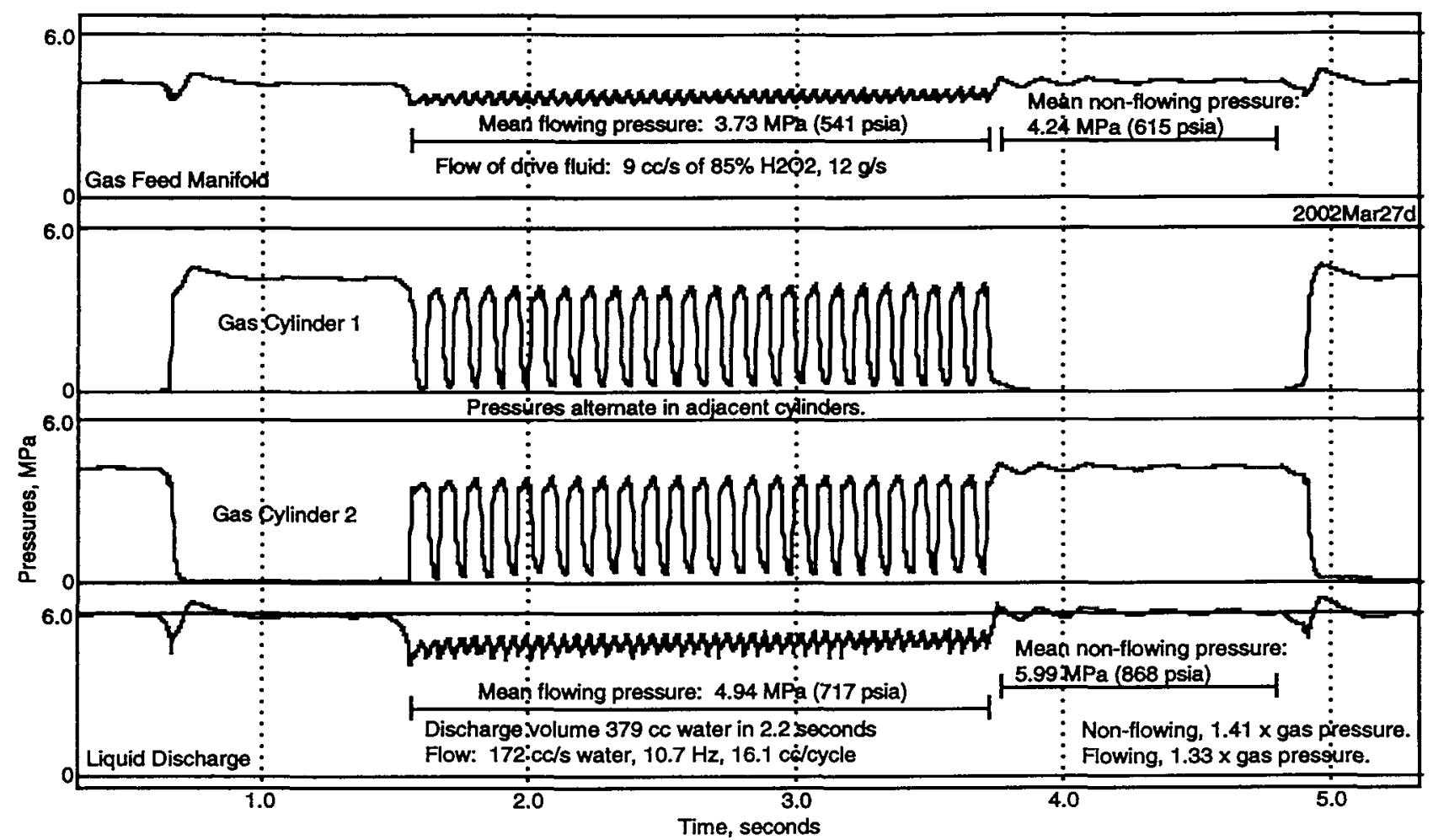

Figure 3. Water flow test of the pressure-boosting quad piston pump, powered by decomposed $85 \%$ hydrogen peroxide.

The gas temperature at the powerhead inlet reached $724 \mathrm{~K}$ (844 F). This is a much faster warmup than in Reference 3 (approx $2 \mathrm{~s}$ versus $4 \mathrm{~s}$ ), which is consistent with the new lightweight gas supply manifold and higher pressures here. In the test of Figure 3, the conductively-cooled aluminum parts remained below $380 \mathrm{~K}$ (224 F) externally.

Over the course of this run, 31 cc of $85 \%$ HTP was consumed through the gas generator. Some of this initially filled volumes (mostly a $75 \mathrm{cc}$ gas accumulator) and was later vented, including condensed water. A test without pump cycling consumed $11 \mathrm{cc}$ of propellant. Subtracting indicates that $20 \mathrm{cc}$ of $85 \%$ HTP was expended to deliver $379 \mathrm{cc}$ of water at $4.94 \mathrm{MPa}$, or just over $5 \%$ by volume. Longer durations would be expected to reduce this, since there is extra steam condensation during warmup.

An average state of the fluid in the full gas cylinders at the end of the power strokes may be determined. Propellant density and the piston area ratio with data above indicates an average bulk density of $52 \mathrm{~g} / \mathrm{l}(27.4 \mathrm{~g} / 530 \mathrm{cc})$ at $3.73 \mathrm{MPa}$. Forty percent by mass of decomposed $85 \%$ HTP is oxygen, $21 \mathrm{~g} / \mathrm{l}$ here. A few iterative steps with water's steep temperature-pressure curve yields a temperature of approximately $460 \mathrm{~K}(368 \mathrm{~F})$. At this point, oxygen at 21 $\mathrm{g} / \mathrm{l}$ has a partial pressure of $2.5 \mathrm{MPa}$, and the vapor pressure of water is 1.2 MPa, which sums to the known total. Steam is thus one third of the gas phase molecules.
At $460 \mathrm{~K}$, the density of saturated steam is $6 \mathrm{~g} / \mathrm{l}$. The remaining 25 grams in each liter of pump drive fluid must have been condensed water, almost half the mass. It is encouraging to note that only modestly higher temperatures would correspond to much less condensation.

The $12.5 \mathrm{~g} / \mathrm{s}$ flow through the gas generator includes $6 \mathrm{~g} / \mathrm{s}$ of condensing steam, for a heat load of $12 \mathrm{~kW}(6 \mathrm{~kW}$ for a given cylinder during its power stroke). This would heat the $172 \mathrm{~g} / \mathrm{s}$ flow of pumped water by $17 \mathrm{~K}$. Such a large rise was not noted during tests. Most likely a significant fraction of the heat is carried away by vaporizing water during exhaust venting.

Figure 4 shows individual pressure pulses in the gas cylinders, and Fig. 5 presents a similar test with helium power. Ideally, the pulses would be square with slight overlap, so that nearly half of the time is available for liquid refill from the low pressure tank. As would be expected, helium approaches this ideal more nearly than oxygen and steam. In the later case, the refill time is restricted, which limits the maximum flow capability of the pump. The design and operation of the intake-exhaust valves would be tailored to the drive fluid for optimized performance. Improvements here could potentially double the pump's flow limit, by doubling the time that the pump cylinder pressure is below tank pressure. 


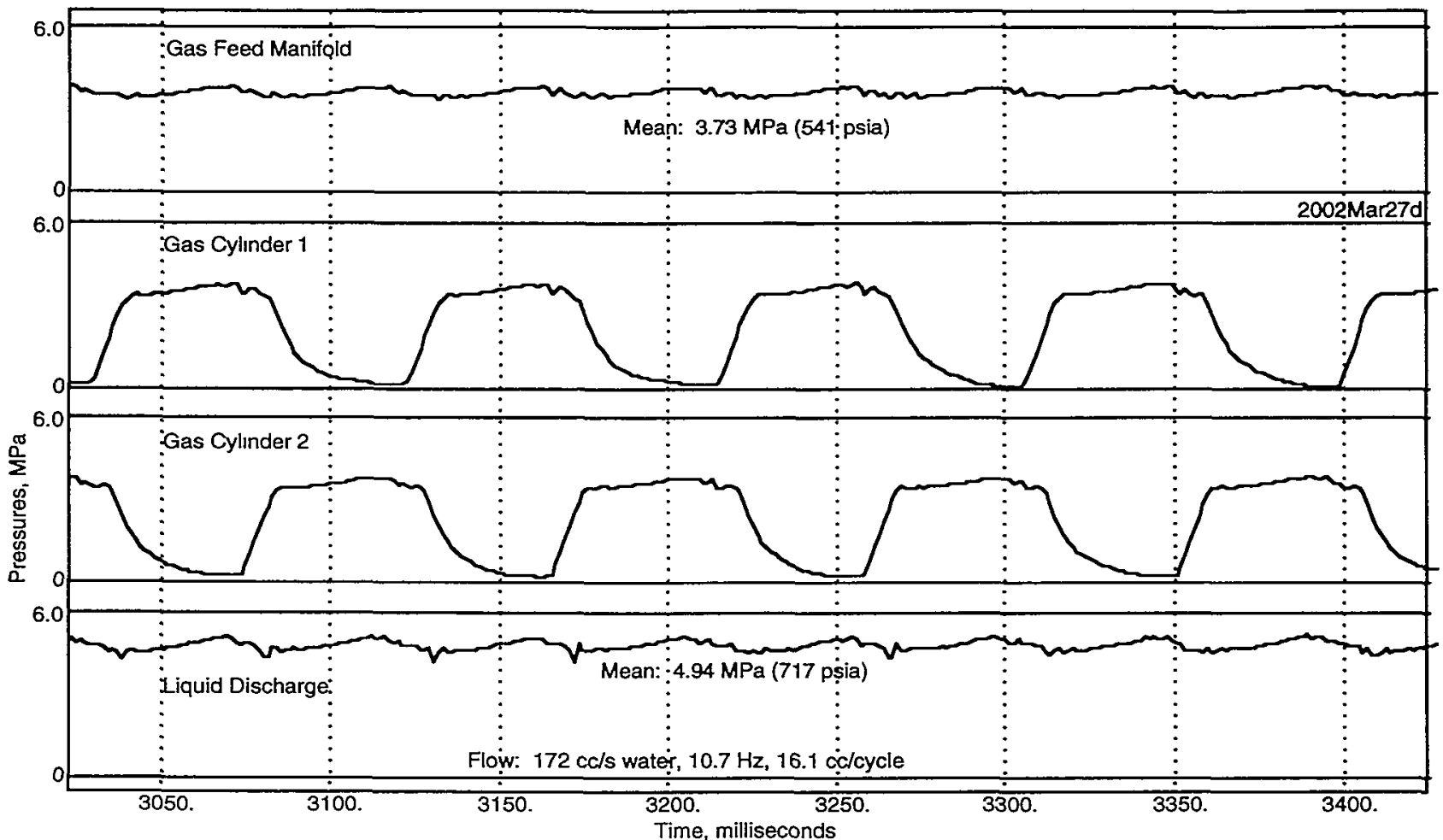

Figure 4. Pressure data from Figure 3 with an expanded time scale, just after $t=3.0$ seconds.

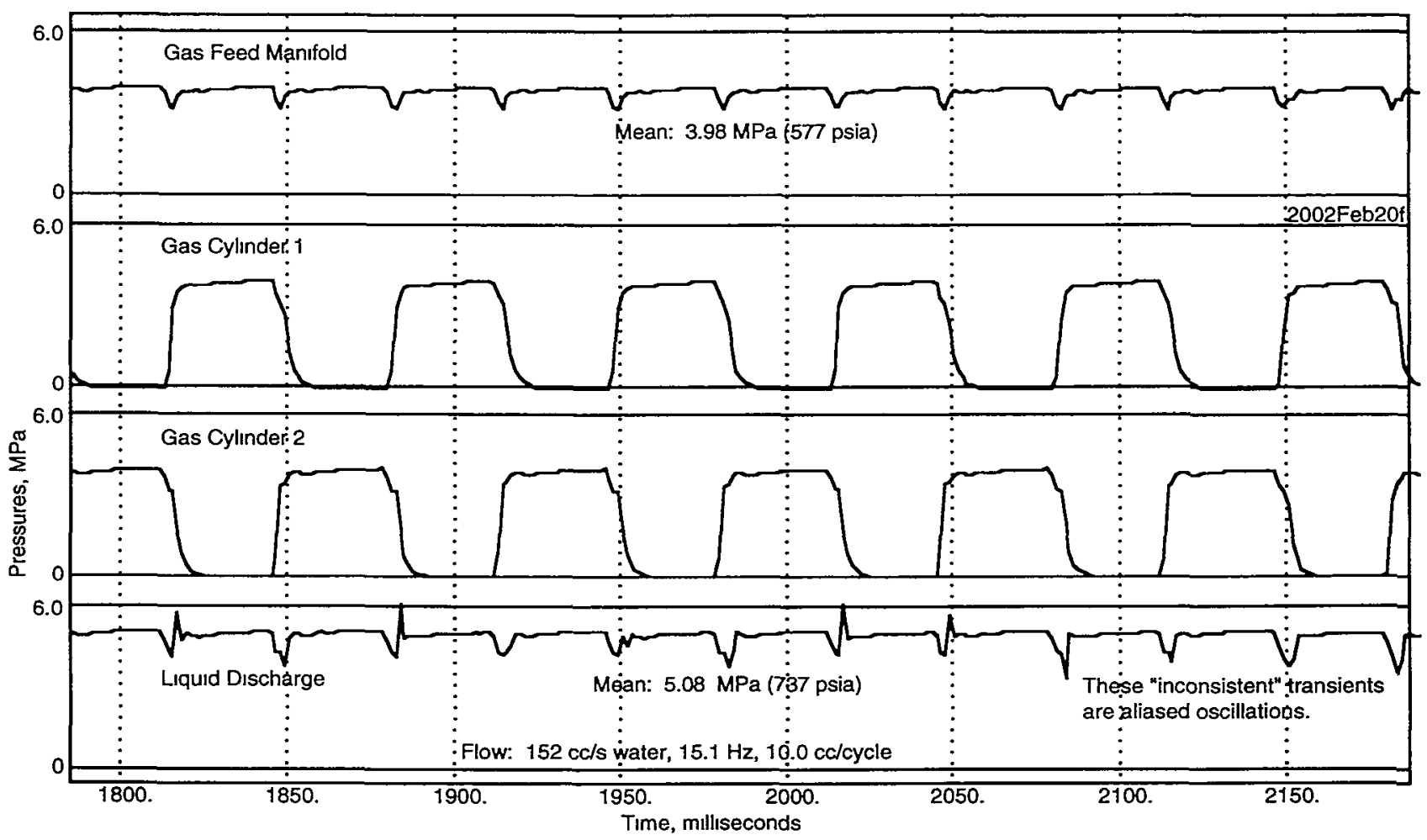

Figure 5. Helium powered water flow test for comparison to Figure 4. 


\section{Monopropellant Gas Generator Cycle}

Figure 6 shows a simplified schematic of a complete rocket system using the pump. This can be implemented with any monopropellant, given appropriate choices for compatible materials and component details, including the decomposition catalyst in the gas generator. More generally, the schematic represents half of a bipropellant system. A key requirement for a gas generator cycle system is that the pump must deliver liquid at a pressure higher than its drive gas. The resulting potential for boundless pressure amplification (with thrusters off) is controlled by the regulator in series with the gas generator.

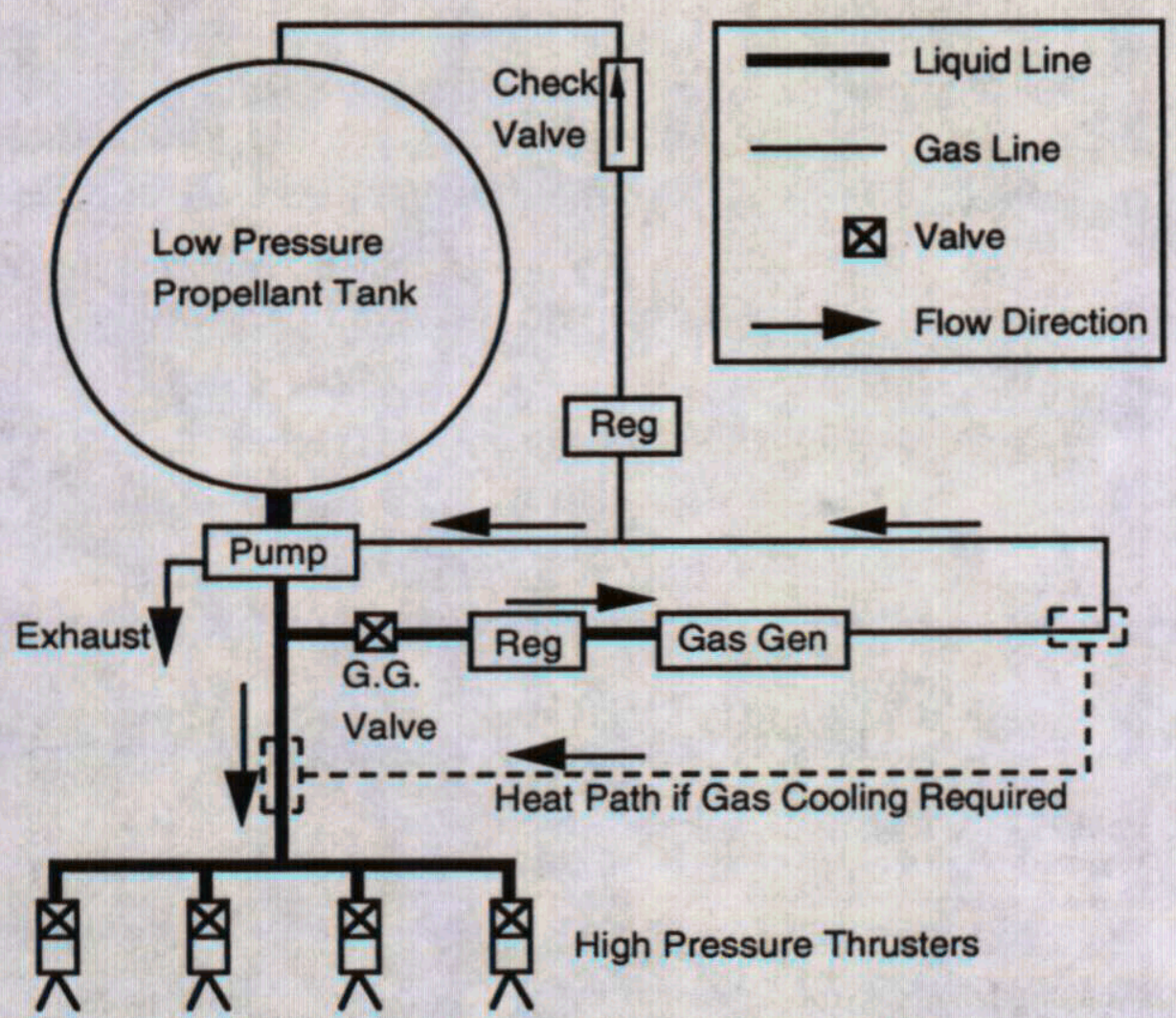

Figure 6. Monopropellant gas generator cycle.

While most of the propellant is pumped directly to one or more thrust chambers, a small fraction of it performs the pumping work. Ideally, this is done at a high gas temperature, since a lower density reduces the amount of propellant required. Other challenges in pump design that follow directly from propulsion system performance requirements include low mass, low leakage, and small size.

Several features in Figure 6 have not been included in tests with HTP to date. A heat exchanger for cooling the gas has not been necessary, and tank repressurization with warm gas has not been implemented yet. More notably, the test data presented below was obtained without thrusters connected to the system, in order to accurately measure delivered propellant mass, while reducing acoustic noise.

Figure 7 shows the breadboard propulsion system that has been tested on numerous occasions this year. The thin plastic low-pressure 2-liter tank holds about 50 times its own mass in propellant. It was pressurized by air at 0.35
$\mathrm{MPa}$ (50 psi) for results reported here, but starts from tank pressure were readily obtained at $0.2 \mathrm{MPa}(30 \mathrm{psi})$.

While more sophisticated propulsion system designs are under concurrent development, this configuration was chosen to simplify initial performance testing. When the tank is vented at the top before and after testing, the possibility of leakage or spillage is avoided. This "upside down" tank uses a large dip tube to feed the pump without flow restrictions.

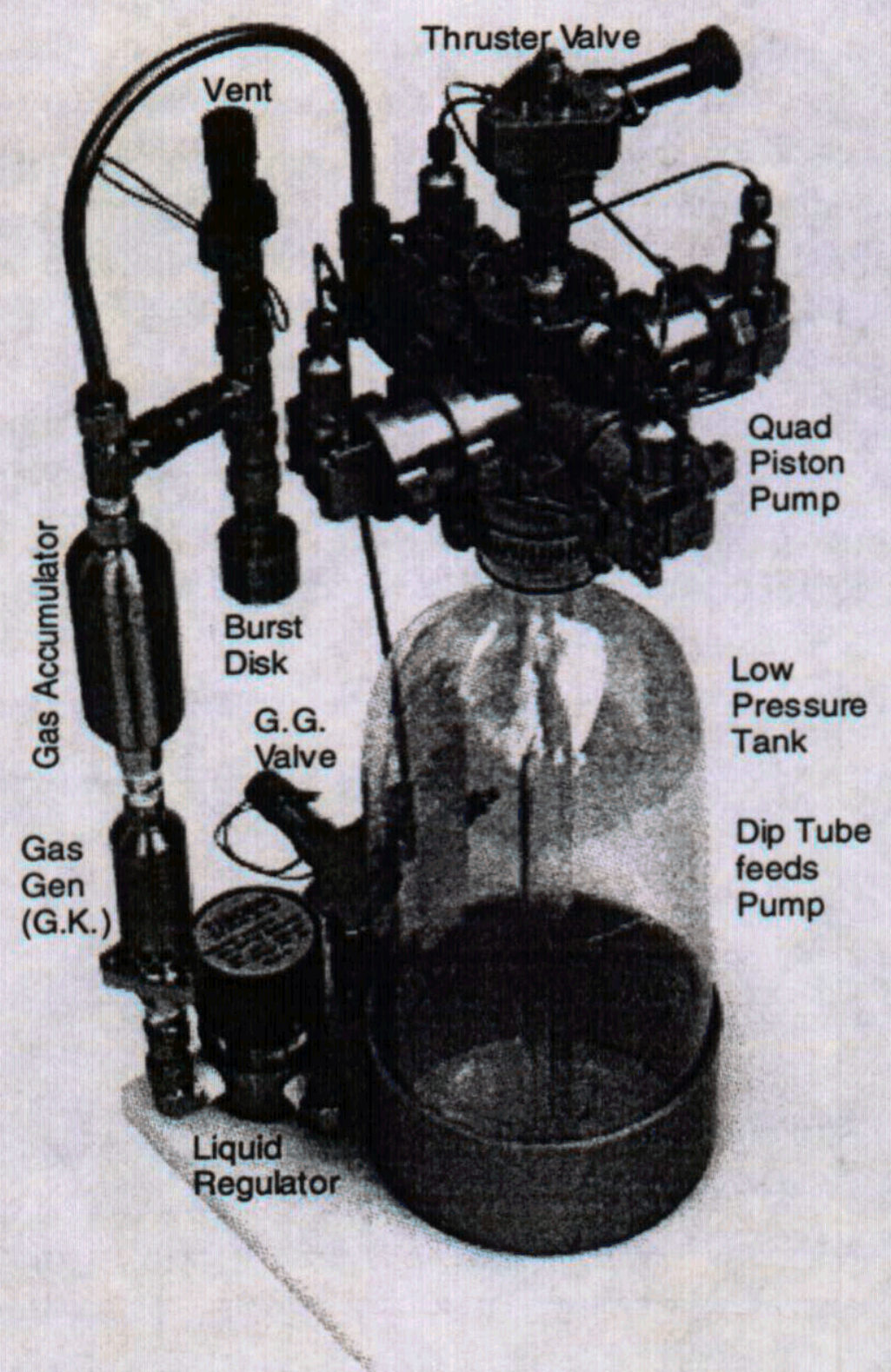

Figure 7. Breadboard gas generator cycle system.

The pump discharge node is bolted on top as oriented here, and the main flow through a thruster valve above that was fed to a collection vessel. The thin (1/8 inch) vertical tube behind the tank feeds the gas generator control valve.

Figure 6 omits several features of the gas plumbing used primarily for test purposes. The $40 \mathrm{cc}$ accumulator in Figure 7 was included as a safety precaution to soften pressure overshoots that could potentially occur during startup, and did on the first tests. This accumulator is smaller than the one used for pump testing, and most likely it will not be needed after system operation is understood 
better and adjusted accordingly. A safety burst disk and a normally open vent valve are connected to the accumulator.

Extra ports on the Tescom regulator were used for pressure transducers. The pump discharge node and the gas supply manifold were instrumented, just as for pump testing. For all tests, a gas immersion thermocouple was adjacent to the pressure tap at the branch point closest to the cylinders.

The whole apparatus shown was placed inside a safety shield box, in a splash container, atop a digital electronic scale. The collection vessel was also in the splash container. In order to obtain accurate mass data, the only external connections were instrument wires and a flexible vinyl air tube for remote pressurization of the tank. Remote venting of the latter returned the system to a safe, completely unpressurized state.

System mass was recorded at critical junctures during the course of several tests performed with each propellant load. The resulting data indicated the total mass of pump exhaust, vented fluid, and leakage (negligible in most cases). In addition, the collection vessel was removed and weighed separately after each test.

\section{$\underline{\text { System Test Results }}$}

After system assembly, loading $85 \%$ HTP, and pressurizing the tank with air, startup is accomplished by closing the vent valve then opening the gas generator valve. Air initially in the dip tube, pump, and other lines must flow through the gas generator, so the first startup after propellant loading requires several seconds duration.

Figure 8 shows the results of a second-of-series test. Note that the liquid discharge pressure is initially at the tank level. Upon actuation of the gas generator feed valve, the regulator pressures and the gas pressure rise in sequence over a period of $0.8 \mathrm{~s}$. Then, the gas pressure load on the pump piston overcomes the tank pressure load, and positive feedback rapidly raises the system to operating pressure within one pump stroke. The regulator shuts and the system maintains pressure without pump cycling.

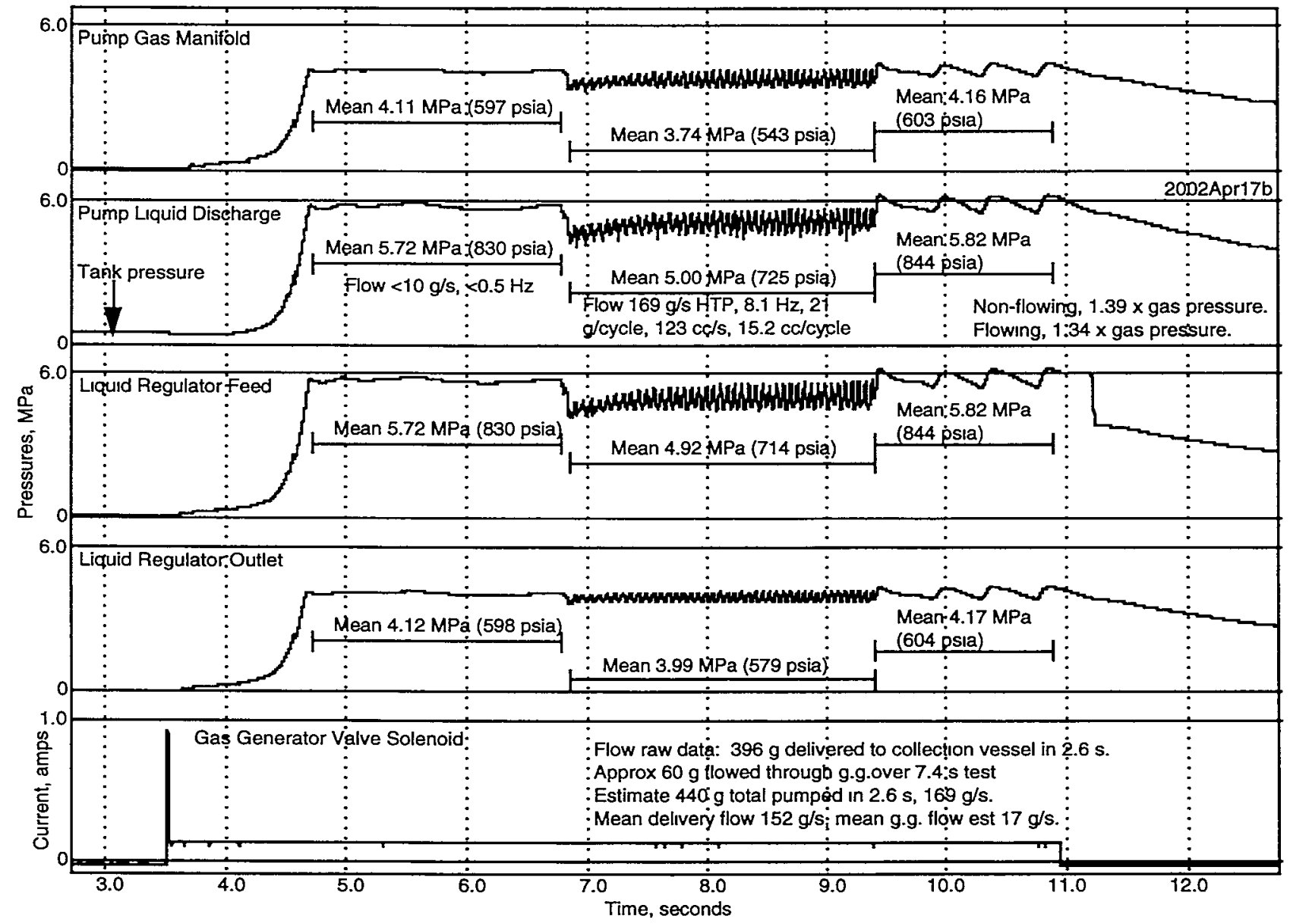

Figure 8. Bootstrap start from tank pressure followed by high pressure propellant delivery from the g.g. cycle system. 
During those 2 seconds, the regulator feed pressure equals the pump discharge pressure, and the loss from the regulator outlet to the powerhead is negligible. Previously, over $10 \%$ of the regulator outlet pressure was wasted in association with gas flow to the leaky hydrazine pump. $4 \& 5$

At $t=6.8 \mathrm{~s}$, the thrust control valve was opened. The flow starts and the pump begins rapid cycling with a reduction in mean pressures for two reasons. One is simply the losses associated with flow, and pump switching transients also reduce the average pressure slightly. The transients are least at the regulator outlet. A faster regulator would reduce these further. A smaller regulator would work, considering the huge margin across this one. In addition, the pressure drops across the gas generator and its feed valve are comfortably low.

After the thruster valve is closed, the pump cycles slowly, but the pressures indicate negligible gas generator flow. Most likely, a suction check valve is seated imperfectly, so the leakage is not wasted. After the gas generator valve is shut, the regulator feed pressure flattens out, then drops precipitously as would be expected. Then all the pressures decay as the system cools and steam condenses.

Figure 9 shows a similar test with over 5 seconds of propellant flow which drained the tank. In both tests, pressures droop lowest during the first half to one second of propellant flow. This is a thermal effect, i.e. the cooler, denser fluid in the powerhead results in greater losses before warmup.

For the tests of Figures 8 and 9, the maximum recorded gas temperatures were $628 \mathrm{~K}(671 \mathrm{~F})$ and $673 \mathrm{~K}(751 \mathrm{~F})$ respectively. These are somewhat cooler than in the pump test of Figure 3, and indeed the total consumption through the gas generator is greater relative to the pump discharge volume flow. This is presently not understood, although it is possible for example that the catalyst in this second gas generator had reduced activity due to some previous unknown event. The gas generator flow in Figure 9 was only $70 \%$ of that in Figure 8, and extrapolation to the temperature of the Figure 3 test would result in a similar efficiency number.

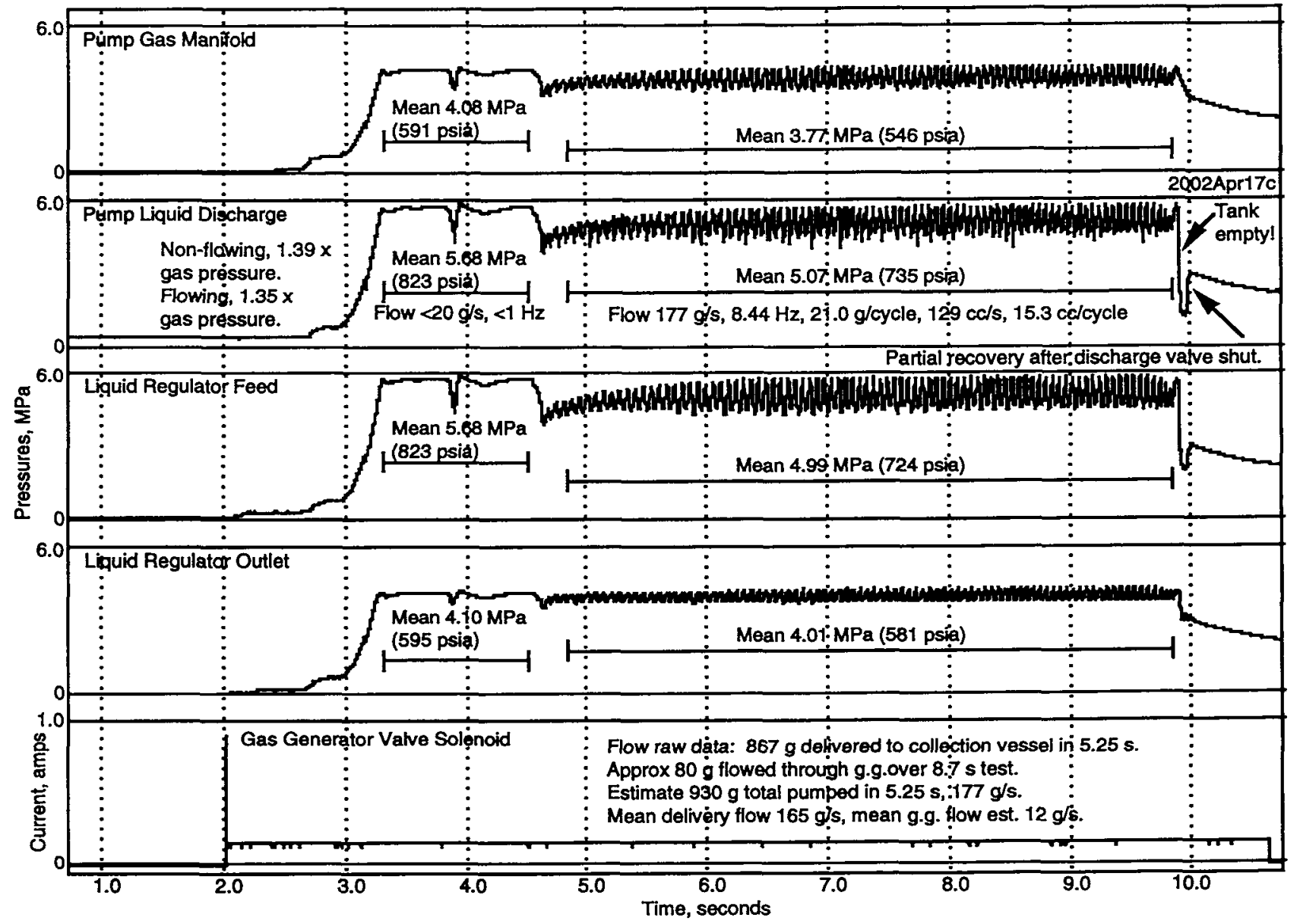

Figure 9. Longer duration system test emptied propellant tank. 


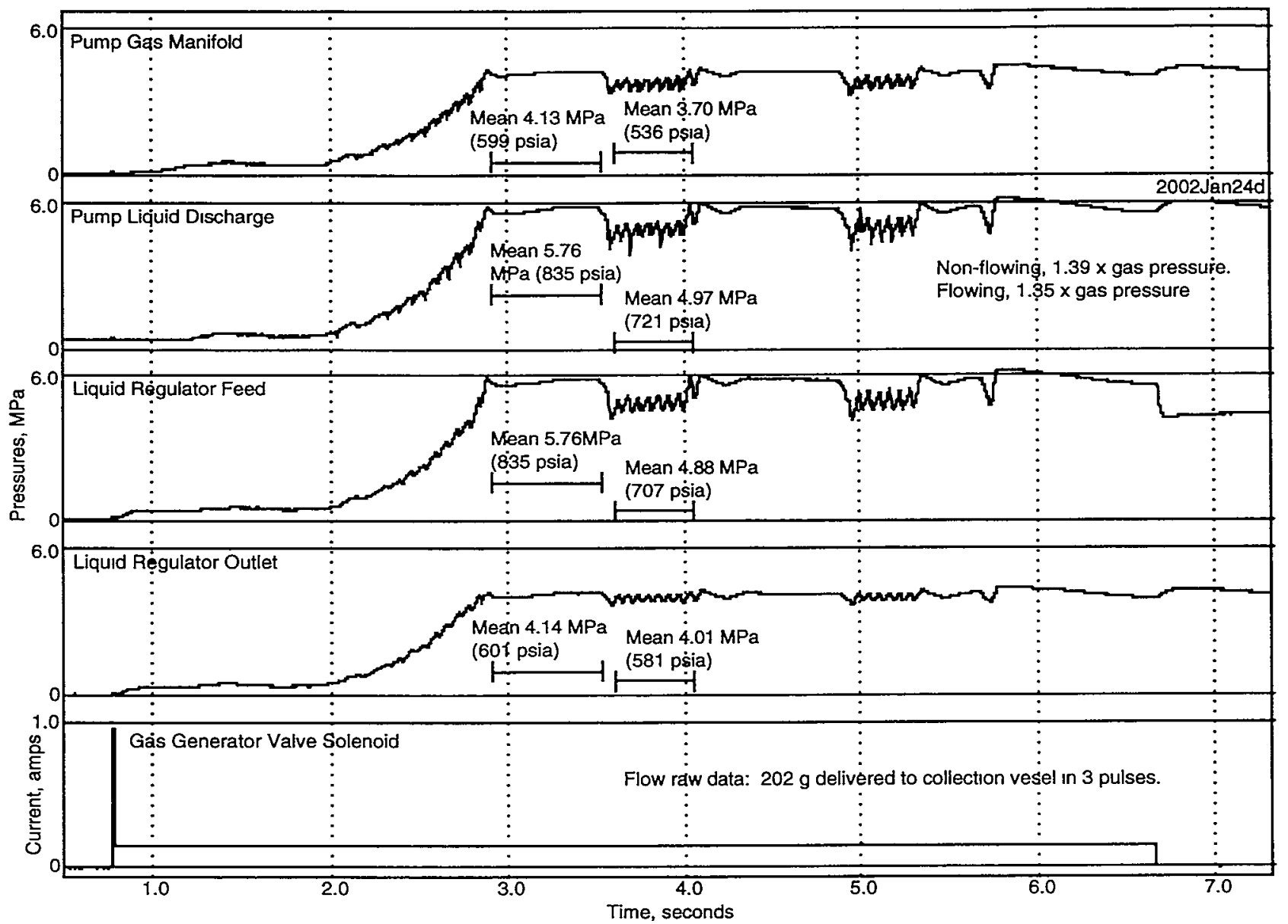

Figure 10. Pulsed propellant delivery. Liquid discharge valve was open during system startup.

Another difference in Figure 9 is that the pressures fall in sequence through the gas generator circuit, when the propellant supply runs out. Note the partial recovery.

Figure 10 shows one more anomalous test condition, to which the system responded robustly. The start was delayed for unknown reasons. The first of 3 propellant delivery pulses was superimposed on the bootstrap start sequence. The pump was cycling rapidly, and the pressure rise was not as steep as in Figures 8 and 9.

In general, the moving pump parts and seals did not wear out or overheat, so that very little refurbishment was required throughout numerous tests similar to the ones described here. Therefore, higher temperatures and longer durations are probably within the hardware's capability.

\section{Discussion}

These are the first test results for a miniature, gas-generator cycle, pump-fed propulsion system with a reciprocating pump, since the hydrazine tests in $1993-1994 .{ }^{2 \& 4 \& 5}$ It is the first successful operation of this type of system with hydrogen peroxide. The overall results are similar, but the warm gas leakage has been eliminated. The pump hardware has about the same mass, but is less costly, since machined aluminum parts have replaced titanium weldments. While the output is less, the difference is most likely attributable to two-phase flow in the intake-exhaust valves and some extra time required for re-vaporization and venting of condensate after the exhaust valve opens.

Nontoxic hydrogen peroxide has lived up to its reputation, given the relative ease of testing a complex, potentially failure-prone system. The number of separate tests recently accomplished with the assembly in Figure 7 rivals the total number of those ever done with the miniature pumped hydrazine systems.

This is largely because hydrazine requires scheduling a particular time slot of a few days in a specialized test facility. The presence of toxic vapors is less compatible with immediate modification and retesting, so it may be necessary to wait months for each successive test. 
The low-pressure tank used here for HTP is very thin and lightweight. The pumped hydrazine tests used heavy facility tanks, due to greater concerns with toxic propellant in a very thin tank. Separate mass measurements of delivered fluid and gas generator flow were not as easy.

Given that innovation and refinement has been facilitated by nontoxic propellant, the development time for a hydrazine system with similar improvements would be less now than it otherwise would have been. Both propellants of course will continue to have their individual advantages. One of the latter's is the absence of condensation in the pump powerhead, which would improve efficiency.

The next step is expected to be system testing with one or more high-pressure HTP thrusters that have been in development this year at subcontractors. It is believed that this ongoing effort is useful progress toward several potential applications. One of these is a miniature launch vehicle capable of lifting geological samples from Mars to orbit, on the way to earth.

\section{Acknowledgment}

This work was sponsored by the U.S. Government and performed by the University of California Lawrence Livermore National Laboratory under Contract W-7405Eng-48 with the U.S. Dept. of Energy.

\section{$\underline{\text { References }}$}

1. Whitehead, J.C. \& G.T. Brewster, High Pressure Pumped Hydrazine for Mars Sample Return, Journal of Spacecraft and Rockets, Vol. 37. No. 4, pp. 532-538, July 2000.

2. Whitehead, J.C., L.C. Pittenger, N.J. Colella, Design and Flight Testing of a Reciprocating Pump Fed Rocket, AIAA 94-3031, 1994.

3. Whitehead, J.C., Test Results for a Reciprocating Pump Powered by Decomposed Hydrogen Peroxide, AIAA 20013839, July 2001.

4. Maybee, J.C., D.G. Swink, J.C. Whitehead, Updated Test Results of a Pumped Monopropellant Propulsion System, JANNAF Propulsion Meeting Proceedings, CPIA Pub. 602 Vol. 1, p. 131, November 1993.

5. Frei, T.E., J.C. Maybee, J.C. Whitehead, Recent Test Results of a Warm Gas Pumped Monopropellant Propulsion System. AIAA 94-3393, 1994. 